Article

\title{
Experimental Study of Steel Reinforced Concrete (SRC) Joints
}

\author{
Isaac Montava *, Ramón Irles, Juan Carlos Pomares $\mathbb{D}$ and Antonio Gonzalez \\ Departamento de Ingeniería Civil, Universidad de Alicante, 03080 Sant Vicent del Raspeig, Spain; \\ ramon.irles@ua.es (R.I.); jc.pomares@ua.es (J.C.P.); antonio.gonzalez@ua.es (A.G.) \\ * Correspondence: isaac.montava@ua.es; Tel.: +34-966-528-428
}

Received: 26 February 2019; Accepted: 9 April 2019; Published: 12 April 2019

\begin{abstract}
This research analyzes the solution of reinforced concrete joints reinforced with steel sections, known as steel reinforced concrete (SRC). The aim is to verify the improvement of the ductile characteristics of steel reinforced concrete structures compared to conventional reinforced concrete structures. Another objective is to better understand the experimental behavior and thus be able to perform numerical simulations adjusted with the experimental ones. In addition, the behavior of reinforced concrete structures in all the bars with steel sections is compared with others in which only the joints are reinforced to obtain more efficient and economical structures. All these objectives have the main purpose of improving the behavior of structures against seismic loads. Five specimens of concrete joints with reinforced with steel were tested with cyclic loads to analyze their behavior. The strength superposition method can predict the shear strength. The results obtained confirm the greater capacity of absorption of energy of the structures with sections of steel embedded compared with the structures of conventional reinforced concrete, with greater ductility when facing large displacements.
\end{abstract}

Keywords: steel reinforced concrete; beam-column joints; earthquake; reinforced concrete; cross-sections; joint; reinforcement

\section{Introduction}

Steel reinforced concrete (SRC) joints, which are composed of reinforced concrete with a steel section embedded inside, are a relatively new structural solution. The joint is the weak point when experiencing seismic action. It is necessary to analyze whether adding reinforcement to this joint will allow it to absorb a large amount of energy to avoid the failure of structures. A higher ductility means greater energy absorption in the case of earthquakes, which increases the deformation that can be achieved without the collapse of structures.

The Architectural Institute of Japan (AIJ) published the first regulation [1] in 1951 for designing steel reinforced concrete structures. In 1967, Furlong [2] carried out the first studies of steel reinforced concrete columns under bending and traction strength. The studies conducted since 1973 by Wakabayasi [3], analyzed the behavior of SRC. This author presented a series of 10 tested cross-shaped specimens. The conclusion was that in terms of design, the method for superposition, which adds the individual resistance of steel, concrete and corrugated rods, was the most adequate for predicting the elastic behavior of a section. The steel cross-section can replace part of the reinforcing bars of reinforced concrete and it is able to dissipate greater energy than conventional reinforced concrete structures.

Mirmiran and Shahawy [4] studied the behavior of confined specimens subjected to static compression loads and to load-unload cycles to evaluate the degradation of reinforcement by verifying that the response was similar in both cases. Gioncu and Petcu $[5,6]$ studied the rotation capacity of double $\mathrm{T}$ steel beams and column-beam joints by a local plastic mechanism. They devised computer 
software determine the rotation capacity of beams, which they compared with experimental tests to obtain consistent results. In these studies, standard beams were used in two types of structures: continuous steel beams and rigid frameworks.

Chen et al. [7] conducted different studies with joint steel reinforced concrete. The results show that SRC joints efficiently dissipated energy. The superposition method was able to accurately estimate joint strength.

The research conducted by Tong et al. [8] analyzed the behavior of reinforced concrete steel beams using cross-sections in H. In her thesis, Giménez-Carbó [9] analyzed reinforced concrete supports strengthened with steel cross-sections. She performed a thorough literature review in the field of reinforced concrete supports. Reinforcement with L-cross-section steel improves the resistance and ductility of the element, which is a satisfactory solution for reinforcement concrete structures to improve their behavior when experiencing earthquakes. In his thesis, Figueirido [10] studied the buckling behavior of rectangular tubular steel cross-sections filled with high-strength concrete under an axial load using a variable bending movement diagram. Chen et al. [11] investigated over 17 specimens with different solutions of steel cross-sections for concrete. They were composed of $\mathrm{L}$ or $\mathrm{T}$ steel cross-sections with reinforced concrete. Their force-displacement graphs are comparable to other numerical studies carried out, such as those by Yan et al. [12], who analyzed the hysteretic curves and introduced the attenuation coefficient to represent the effects of seismic damage. They proposed a model that considers seismic damage and compared the model of hysteretic curves with experimental ones.

Chen et al. [13] used a conventional test frame with a loading-unloading cycle. Recent research, such as that of Chen and $\mathrm{Wu}$ [14], have shown that high-strength reinforced concrete structures, confined with tubular cross-sections and embedded steel cross-sections, display the best behavior.

In this paper, the main failure modes of columns were caused by bending. The latest break occurred in the beam cross-section next to the joint, which is where most of the bending stress is absorbed. The ductility coefficients were greater than 3 , and are calculated as the quotient of the displacement corresponding to the ultimate load and the displacement corresponding to the load of the elastic limit. The constructive solution of the tubular cross-section for reinforcing joints is interesting as the tubular cross-section can be filled with high-strength concrete in the workshop to appreciably increase resistance and to improve the joint's behavior. Steel reinforced concrete is a structural system that has been used in many countries with high levels of seismic risk. The behavior of the reinforced concrete structures, which incorporates a steel cross-section, improves the ductility of the section and its capacity to absorb energy while protecting the steel structure from fire.

Therefore, the reinforcement of joints is very useful when there is high seismic risk as it will considerably improve the structure's overall ductility, particularly in buildings that should offer more safety when earthquakes occur, such as hospitals, schools, congress centers, theaters, cinemas, etc. One of the advantages of steel reinforced concrete is that the prefabrication of these joints reduces the reinforcement of the concrete in the joint, which is usually a difficult element to build. In recent years, there have been numerous scientific studies analyzing the behavior of steel reinforced concrete joints.

In [15] the authors investigate the corner-positioned reinforced concrete beam-column joints in order to study their seismic behavior and to establish the strength in the case of failure of beam-column joints. Santarsiero [16] proposes simple strengthening solutions created by Fibre Reinforced Polymers (FRP) systems that are able to effectively improve seismic resistance. The performance characteristics of four previously tested beam-column joints reinforced with different configurations are compared to assess their capacity to endure extreme loading [17]. Gribniak et al. [18] investigates the mechanical behavior of steel fiber-reinforced concrete (SFRC) beams that were internally reinforced with steel bars and externally bonded with carbon fiber-reinforced polymer (CFRP) sheets fixed by adhesive and hybrid jointing techniques. Regarding the role of steel fibers, the effects of the addition of fibers with different geometries and aspect ratios on the mechanical properties of SFRC might significantly vary [19]. Recently, other studies, including [20] have analyzed the shear strength. 


\section{Methodology}

The tests were conducted using cycles of loading and unloading. Tests were performed on a joint between two beams and a column, in which a cyclic loading-unloading test, with no load in the opposite direction, was carried out on the column in order to obtain an understanding of the joint's behavior. The test was repeated with different sections: reinforced concrete and steel reinforced concrete. The embedded cross-section was only in the joint (see Figure 1).

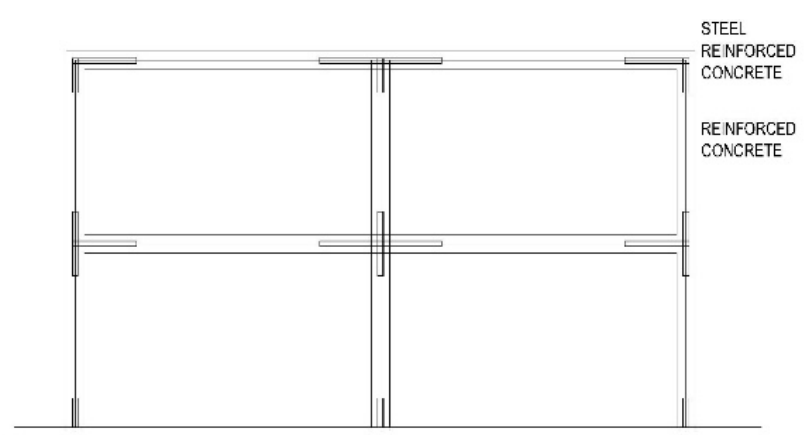

Figure 1. Detail of the steel cross-section reinforcement only in the joints.

Tests were carried out in the loading framework of the laboratory, which can apply a maximum load of $300 \mathrm{kN}$ (Figure 2).

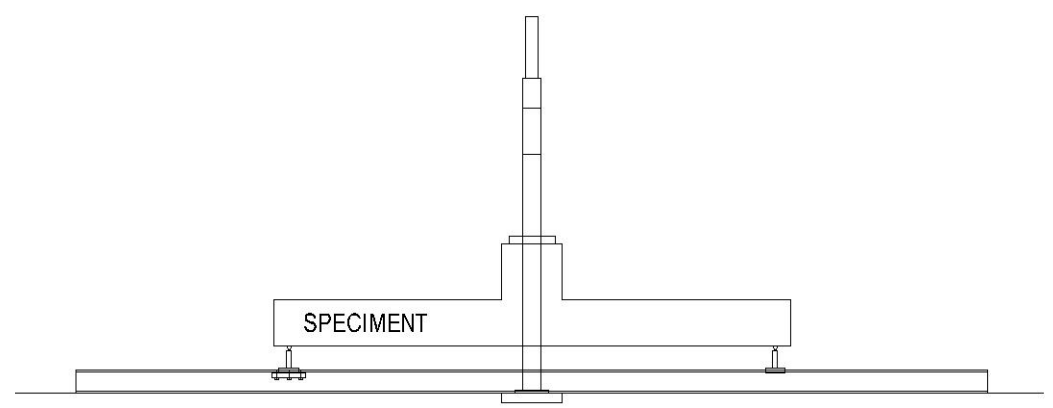

ELEVATION

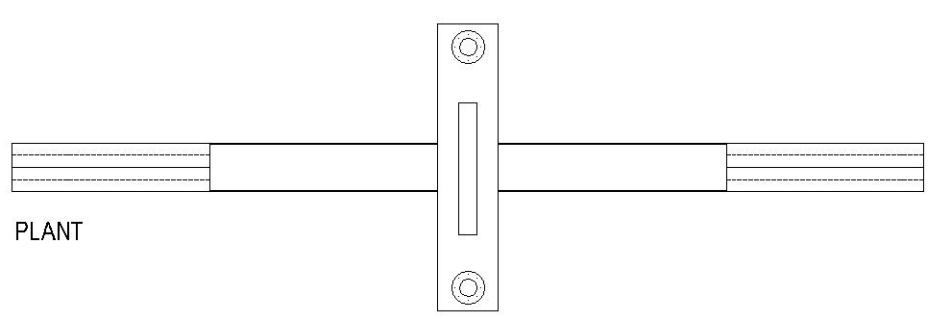

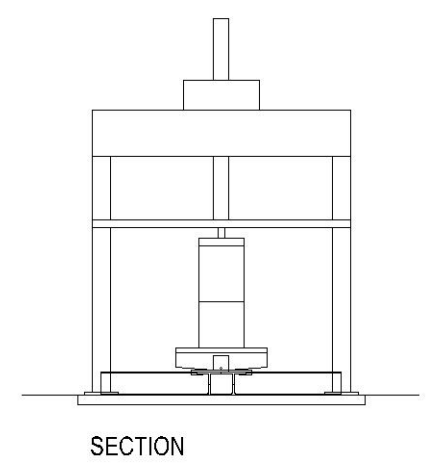

SECTION

Figure 2. Loading framework.

Specimens were designed with steel cross-sections to reinforce the joints of the singular points of the structures subjected to strong earthquakes. Under earthquake action, an asymmetric and cyclic bending moment diagram takes place due to the dynamic effect of loading and unloading. The bending of a framework against horizontal forces are distributed according to Figure 3.

The tested joint corresponds to a T-joint of a conventional framework with a point load in the center, which may correspond to a horizontal or vertical load. Given the test frame's characteristics, the T-shape was chosen, which corresponds a T-joint that belongs to a conventional building structure frame. 


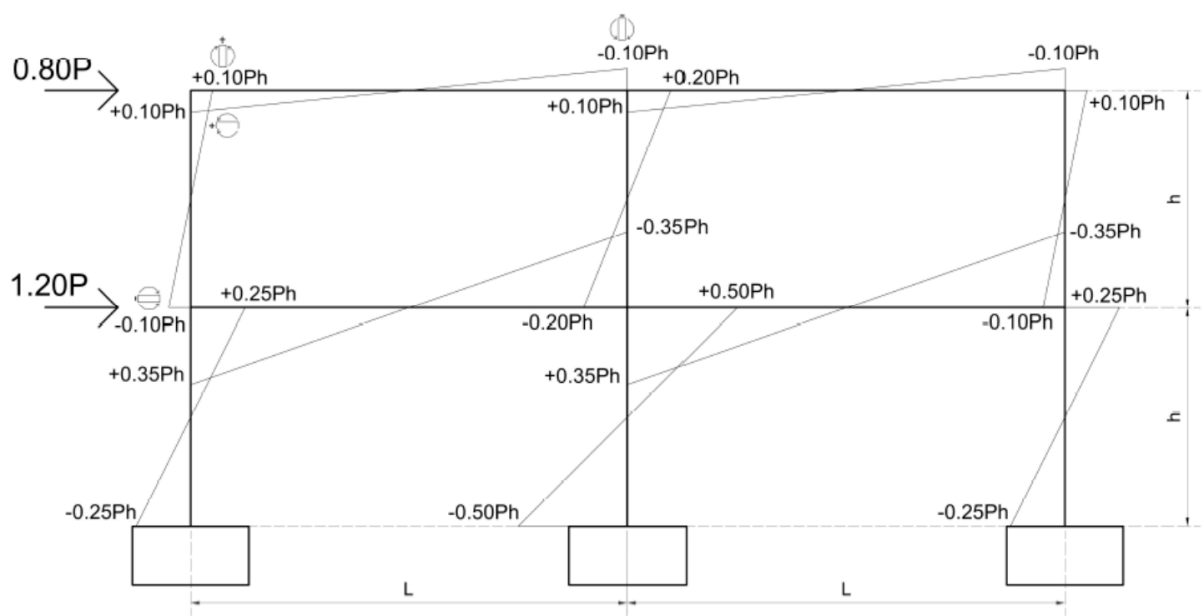

Figure 3. Typical bending arrangement in the event of an earthquake.

Different constructive solutions of the framework's representative beam were subjected to a cyclic loading and unloading process to obtain an understanding of its real behavior in the elastic and plastic phases up to breakage, which was achieved only in less ductile assemblies. Load is introduced as a displacement imposed at the center of the beam. The displacement values obtained are repeated twice in the load-unload cycles. They increased and progressed in a parabola until the maximum displacement of $330 \mathrm{~mm}$ (Figure 4).

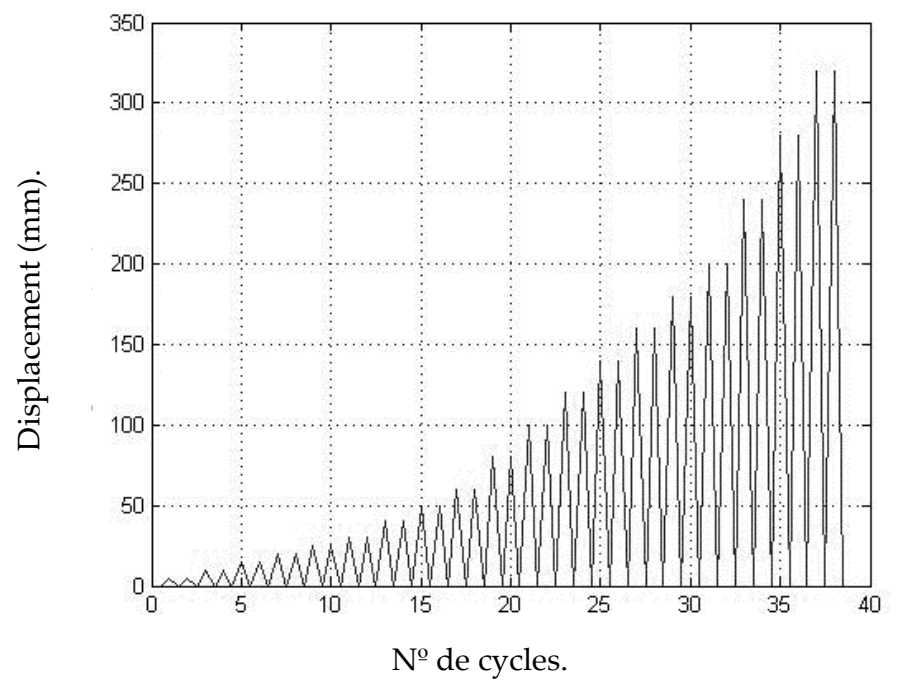

Figure 4. Loading history in displacement control.

The arrangement of supports and the produced rotation do not allow larger deflections in the center. The tests that were run corresponded to a symmetrical bending distribution in Figure 5A. The asymmetric distribution in Figure 5A corresponds to tests similar to those run by Chen et al. [7]. 


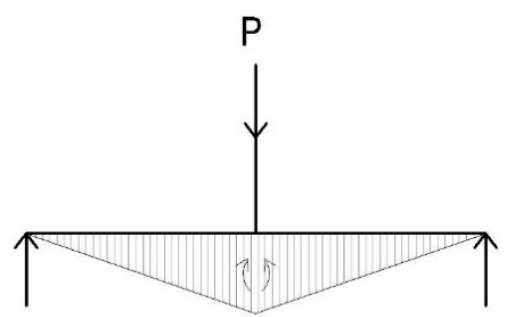

(A)

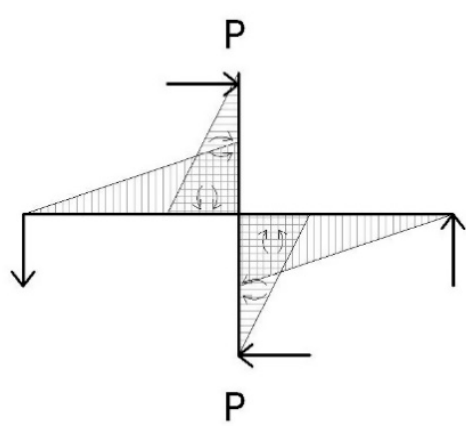

(B)

Figure 5. (A) Symmetric distribution in the joint. (B) Asymmetric distribution in the joint.

However, the absorbed energy is the same for bending in the same direction throughout the length of the bar (Figure 5A), which is the tested case, and also the same for bending with the inverted sign from the joint (Figure 5B). Therefore, both cases are valid for simulating the real behavior of a structure affected by an earthquake.

The absorbed energy is calculated as:

$$
\mathrm{W}=\lambda \cdot \int_{e}^{l} \cdot \mathrm{M}(x) \cdot \chi(x) \cdot \mathrm{d} x
$$

where W: total energy absorbed.

$\lambda$ : elastic coefficient, $\lambda=1 / 2$ in the elastic phase and $\lambda=1$ in the perfect plastic phase.

$l$ : length.

$\mathrm{M}(x)$ : bending moment.

$\chi(x)$ : curvature.

The curvature $\chi$ and bending moment $M(x)$ have the same sign in each section regardless of the direction of bending, which always results in a positive value.

Figure 6 shows the hysteretic behavior of the specimens tested without (6A) and with (6B) load inversion.

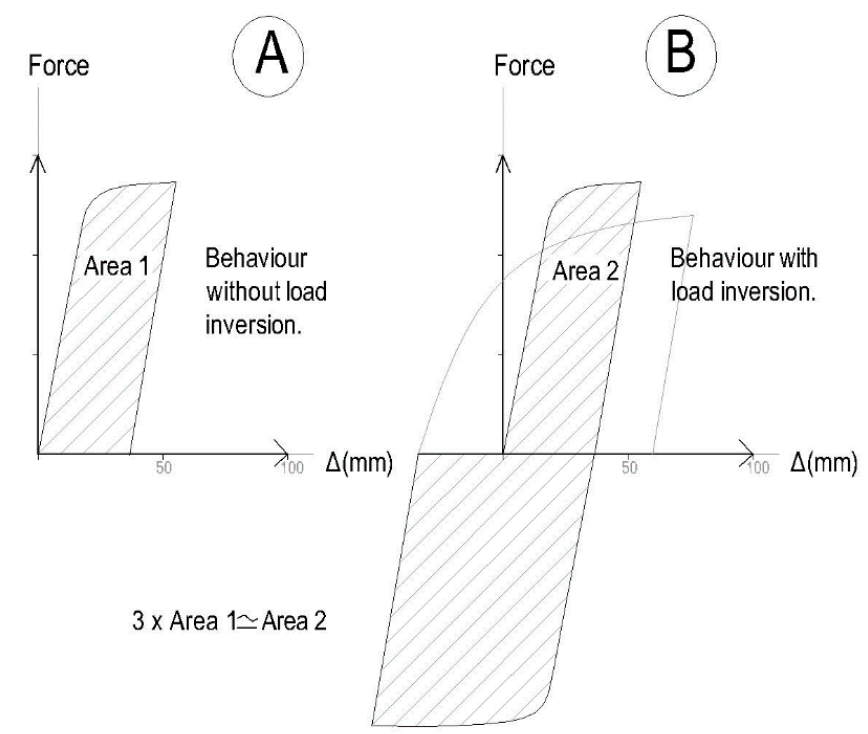

Figure 6. Graph with the tested hysteretic behavior without load inversion (A) and with load inversion (B). 
The force-displacement graphs obtained in the tests of the load form part of those that can be obtained with load-unload cycles. The results are comparable to a bilinear behavior with a linear elastic section and another plastic curved section. The loss of stiffness in (A) is less in the tests as the damage caused when the load moves in the opposite direction (B) increases when the concrete at the other end of the section is fractured by pulling.

\section{Experimental Program}

\subsection{General Behavior}

The designed T-shaped specimens were tested in a Servosis test frame (model ME-406/30, Servosis, Madrid, Spain), which can apply a maximum force of $300 \mathrm{kN}$. The load can be applied as force/time or displacement/time.

The vertical load was applied to each structural specimen. The design of specimens followed the guidelines of code ACI 318-05 [21] and Eurocode 4 [22]. The purpose of this task was to understand the strength behavior of each solution in the joints with different reinforcements. (Figure 7).

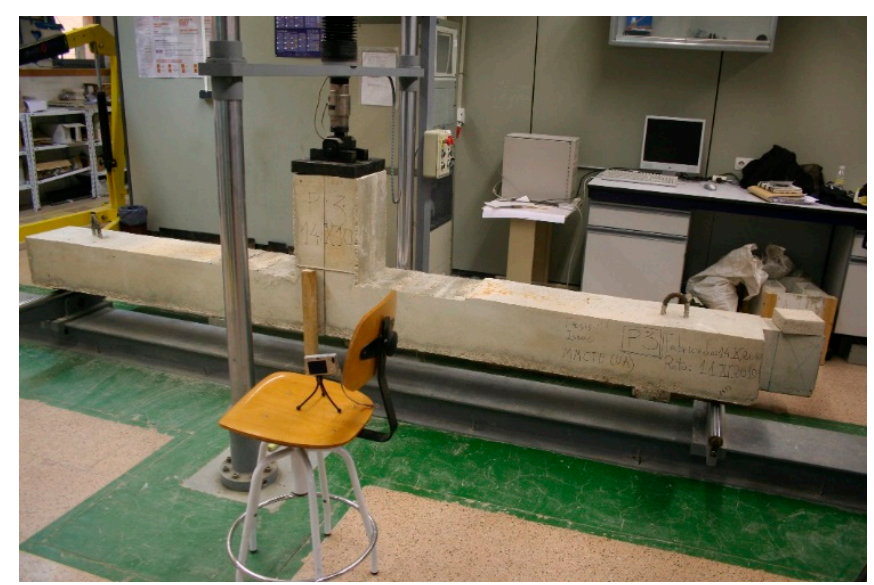

Figure 7. Framework of the tests run in the Department of Civil Engineering laboratory.

Specimen concrete tests were conducted to know the compression strength of the concrete. The aim was to manufacture a structural concrete in the laboratory that is similar to that supplied in construction work. The objective of the tests was for the equipment to cause the specimens to break. For this purpose, gray cement type CEM-42,5 was selected, in which the dose is similar to the mixture of the aggregate used in building concrete plants.

Each specimen has a volume of about $360 \mathrm{dm}^{3}$ which, along with the six cylindrical test pieces needed to check concrete strength, was estimated to be about $400 \mathrm{dm}^{3}$ of concrete. The concrete was manufactured with four mixes of $100 \mathrm{dm}^{3}$ in a concrete mixer at the same dose.

The characteristics of the materials used and the results of the tests can see in Table 1.

Table 1. Properties of the materials used in the specimens.

\begin{tabular}{cccc}
\hline Material & Name & Elastic Limit & Limit of Break Tested \\
\hline Concrete & HA-25/F/20/I & Fck $=25 \mathrm{~N} / \mathrm{mm}^{2}$ & Fce $=3200 \mathrm{~N} / \mathrm{mm}^{2}$ \\
Reinforcing bars & B-500-SD & Fsk $=500 \mathrm{~N} / \mathrm{mm}^{2}$ & Fse $=619 \mathrm{~N} / \mathrm{mm}^{2}$ \\
Steel section & HEB-100-S275 & Fak $=275 \mathrm{~N} / \mathrm{mm}^{2}$ & Fae $=335 \mathrm{~N} / \mathrm{mm}^{2}$ \\
\hline
\end{tabular}

Eight specimens were simulated (Figure 8). Specimens P01 and P02 served to confirm the feasibility of the research line and to adjust specimens P03 and P04 with smaller cross-sections (Figures 8 and 9) in order to ensure that they are better adapted to the maximum load of the test frame. Specimen P03 
was a beam with a section of $30 \times 25 \mathrm{~cm}$ and four reinforcing bars of a diameter of $12 \mathrm{~mm}$. The distance between supports was $3.3 \mathrm{~m}$.

\section{P01 RC}

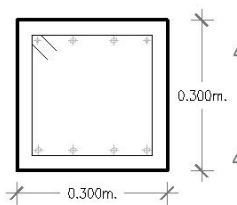

P02 SRC

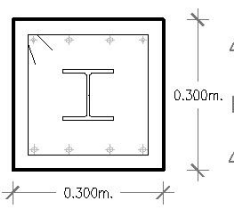

$\underline{P 03 R C}$

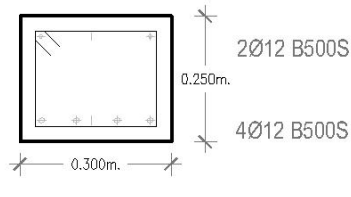

P04 SRC

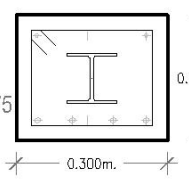

P05 RC

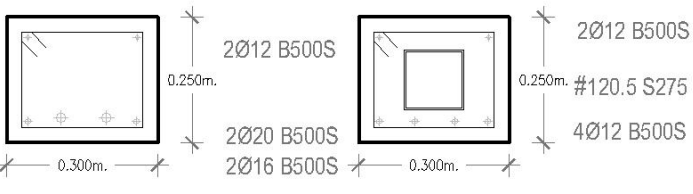

P06 SRC

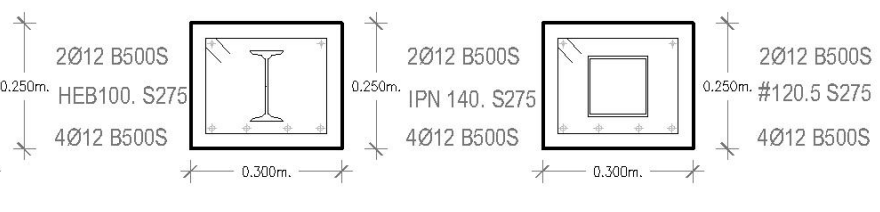

P07b SRC

Figure 8. Cross-sections of specimens.

The reaction force $R$ at the beam ends is calculated using Equation (2) and the beam bending moment at the column surface $\mathrm{Mb}$ can be obtained with Equation (3), according to equilibrium conditions, where $\mathrm{P}$ is the applied load and $\mathrm{Lb}$ is the length, as indicated in Figure 9.

$$
\begin{aligned}
\mathrm{R} & =0.5 \mathrm{P} \\
\mathrm{Mb} & =\mathrm{R} \times \mathrm{Lp}
\end{aligned}
$$

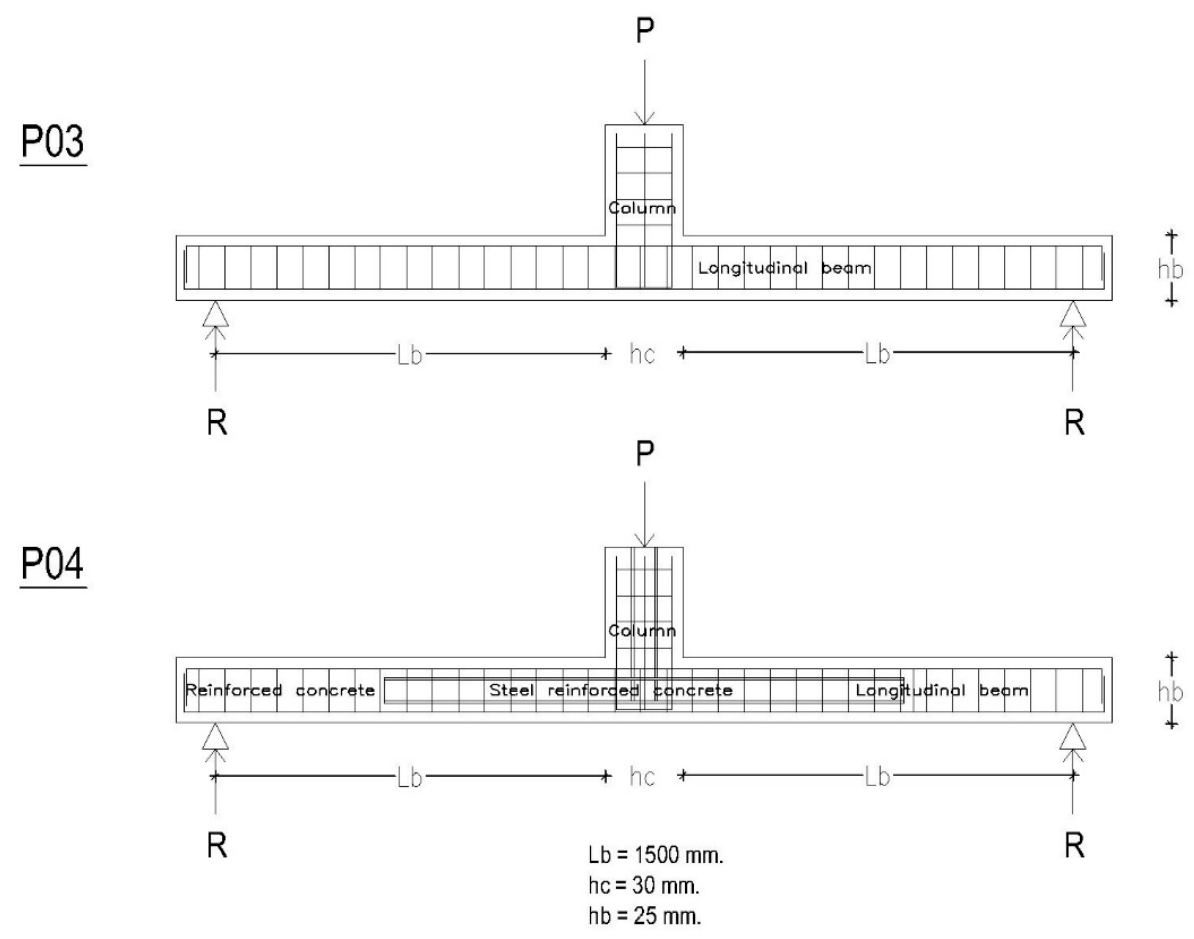

Figure 9. Elevation view of specimens P03 and P04.

The specimen P04 had a steel section HEB 100 completely embedded, with the same reinforcing bars of P03. A steel section embedded in a T-shape, of two meters, in the longitudinal part of the beam and half a meter in the column, was introduced as reinforcement in the joint. The metallic profile was an HEB 100. P05 had with no steel section, but had P04's strength and large deflections. The specimen 
P06, with a steel section HEB 100 IPN 140, was designed to support the bending stress more efficiently than the HEB if it is oriented according to its greater inertia.

- P07a had a square hollow profile of $140 \mathrm{~mm}$ and $5 \mathrm{~mm}$ of thickness. This specimen cracked in the transition between the hollow profile and the reinforced concrete section. First the hollow profile was filled with concrete and after hardening, the rest of specimen was executed.

- $\quad \mathrm{P} 07 \mathrm{~b}$. This specimen was made by testing the previous one and checking that the plastic hinge appears in the transition between the hollow profile and the reinforced concrete section. This transition zone was reinforced with two $20 \mathrm{~mm}$ diameter bars on both sides to ensure the crack near to the joint.

Different construction solutions of the representative beam of the framework (see Table 2) were submitted to a cyclic loading and unloading process to achieve the behavior in elastic and plastic phases. The loads were introduced as a function of displacement to time imposed on the center of the beam, as shown in Figure 4.

Table 2. Table summarizing the tests carried out.

\begin{tabular}{|c|c|c|c|c|c|c|c|c|c|}
\hline Specimen & Typology & $\begin{array}{l}\text { Beam } \\
\text { Section } \\
\left(\mathrm{mm}^{2}\right)\end{array}$ & Lower Bars & Cross-Section & $\begin{array}{l}\text { Distance } \\
\text { between } \\
\text { Supports }\end{array}$ & $\begin{array}{c}\text { Inertia } \\
\text { Cross-Section } \\
\times 10^{4}\left(\mathrm{~mm}^{4}\right)\end{array}$ & $\begin{array}{l}\text { Steel } \\
\text { Weight } \\
(\mathrm{Kg} / \mathrm{m})\end{array}$ & $\begin{array}{c}\text { Theoretical } \\
\text { Maximum } \\
\text { Moment } \\
\text { Mpl,Rd (kN·m) }\end{array}$ & $\begin{array}{l}\text { Maximum } \\
\text { Load }(k N)\end{array}$ \\
\hline P03 & $\mathrm{RC}$ & $300 \times 250$ & $4 \Phi 12$ & - & $3.30 \mathrm{~m}$ & - & - & 50.96 & 67.90 \\
\hline P04 & SRC & $300 \times 250$ & $4 \Phi 12$ & HEB-100 & $3.30 \mathrm{~m}$ & 449.5 & 20.40 & 95.20 & 126.93 \\
\hline P05 & $\mathrm{RC}$ & $300 \times 250$ & $2 \Phi 16+2 \Phi 20$ & - & $3.30 \mathrm{~m}$ & - & - & 95.00 & 126.66 \\
\hline P06 & SRC & $300 \times 250$ & $4 \Phi 12$ & IPN-140 & $3.30 \mathrm{~m}$ & 573 & 14.40 & 79.38 & 105.84 \\
\hline P07a & SRC & $300 \times 250$ & $4 \Phi 12$ & $140 \times 140 \times 5$ & $3.30 \mathrm{~m}$ & 780 & 20.50 & 95.29 & 127.05 \\
\hline P07b & SRC & $300 \times 250$ & $4 \Phi 12$ & $140 \times 140 \times 5$ & $3.30 \mathrm{~m}$ & 780 & 20.50 & 95.29 & 127.05 \\
\hline
\end{tabular}

\subsection{Column Compression Strength Prediction of SRC Joints.}

According to Eurocode 4 [22], the plastic compression strength of the sections can be calculated against axial load, using Eqaution (4). The strength superposition method was able to estimate the SRC column compression strength.

$$
\mathrm{Npl}, \mathrm{Rd}=\mathrm{Aa} \mathrm{fy} / \gamma \mathrm{a}+\mathrm{Ac}(0,85 \mathrm{fck} / \gamma \mathrm{c})+\text { As fsk } / \gamma \mathrm{s}
$$

where $\mathrm{Aa}, \mathrm{Ac}$ and As indicate the respective areas of steel section, concrete and reinforcing bars; fy, fck and fsk indicate the axial strength limits of break testing of the materials; and $\gamma \mathrm{a}, \gamma_{\mathrm{c}}$ and $\gamma \mathrm{s}$ indicate the safety coefficients of the materials.

\subsection{Bending Moment Strength Prediction of SRC Joints.}

In the pre-break phase the section was plasticized (Figure 10).

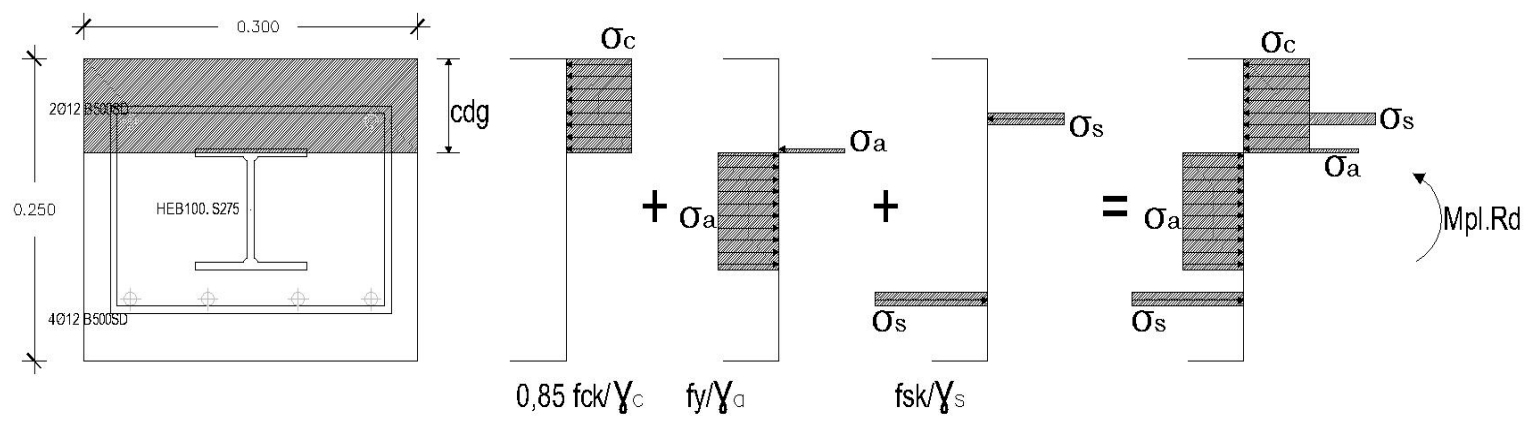

Figure 10. Tension state of pre-rupture of the specimen P04. 
Using the strength superposition method, Equation (5), the bending moment strength of the SRC beam-column joint $\mathrm{Mpl}$, Rd is:

$$
\mathrm{Mpl}, \mathrm{Rd}=\mathrm{Wpa} \mathrm{fy} / \gamma \mathrm{a}+\mathrm{Wpc} 0,85 \mathrm{fck} / \gamma \mathrm{c}+\mathrm{Wps} \mathrm{fsk} / \gamma \mathrm{s}
$$

where $\mathrm{Wpa}, \mathrm{Wpc}$ and $\mathrm{Wps}$ indicate the plastic module of steel section, concrete and reinforcing bars.

\section{Experimental Results}

The results that were obtained in the different tested specimens (see Table 3) were compared. The strength and ductility of the P04 and P06 specimens, which respectively used HEB100 and IPN140 as the embedded steel cross-section, were remarkable. As the latter weighed less than the former, the solution with IPN was more economical with proportional mechanical characteristics.

It is important to note that for strong deformations, the specimen $\mathrm{P} 07 \mathrm{~b}$ had considerably less resistance than P04 due to the greater flexural efficiency of the HEB cross-section than the square tube. The thickness of the HEB flanges is $10 \mathrm{~mm}$ compared to the $5 \mathrm{~mm}$ of the square tube so the HEB section had better resistance against flange buckling.

The maximum load that each specimen was able to support was relevant data, but the maximum deflection that it was able to reach and the ultimate load corresponding to that deflection were more relevant.

Table 3. Summary of the displacements, moments and energy absorbed of the tested specimens.

\begin{tabular}{|c|c|c|c|c|c|c|c|c|}
\hline Specimen & $\begin{array}{c}\text { Maxim } \\
\text { Deflection } \\
\Delta \mu(\mathrm{mm})\end{array}$ & $\mu \Delta \mu / \Delta \mathbf{e}$ & $\begin{array}{c}\text { Moment at } \\
\text { Break } \\
(\mathbf{k N} \cdot \mathrm{m})\end{array}$ & $\begin{array}{l}\text { Elastic Moment } \\
\text { Last of the } \\
\text { Cross-Section } \\
\text { Theoretical } \\
(\mathrm{kN} \cdot \mathrm{m})\end{array}$ & $\begin{array}{l}\text { Plastic Moment } \\
\text { Last of the } \\
\text { Cross-Section } \\
(\mathrm{kN} \cdot \mathrm{m})\end{array}$ & $\begin{array}{c}\text { Maximum } \\
\text { Moment } \\
(\mathbf{k N} \cdot \mathrm{m})\end{array}$ & $\begin{array}{l}\text { Absorbed } \\
\text { Energy } \\
(\mathrm{kN} \cdot \mathrm{m})\end{array}$ & $\begin{array}{l}\text { Maximum } \\
\text { Load }(k N)\end{array}$ \\
\hline P03 & 220 & 7.8 & 41.25 & - & - & 55.00 & 14.65 & 73.33 \\
\hline P04 & 330 & 11.7 & 75.00 & 24.75 & 28.65 & 109.50 & 44.88 & 146.55 \\
\hline P05 & 220 & 7.8 & 41.25 & - & - & 108.75 & 23.11 & 145.10 \\
\hline P06 & 280 & 10 & 75.00 & 22.52 & 26.23 & 97.50 & 38.84 & 130.72 \\
\hline P07a & 170 & 6 & 82.50 & 30.52 & 36.28 & 123.75 & 35.10 & 165.15 \\
\hline P07b & 350 & 12.5 & 82.50 & 30.52 & 36.28 & 116.25 & 47.99 & 155.20 \\
\hline
\end{tabular}

The structural ductility $(\mu=\Delta \mu / \Delta \mathrm{e})$ was one of the most important indices for evaluating resistance capacity against earthquakes. At the maximum deflection of specimen P04, the moment at break was $75 \mathrm{kN} \cdot \mathrm{m}$, which was almost three times the maximum moment that the cross-section resisted in a plastic regime. hat section was able to resist higher deflections than the others tested. In specimen P03, the last break was fast and fragile since the traction bars broke, which ultimately caused the structure to break.

Specimen P04 was made as shown in Figure 11A. The reinforcement bars were located around the steel cross-section. Finally, the steel bars and the steel cross-section were placed inside the framework in a $\mathrm{T}$ shape.

The ultimate breakage of the beam could not be achieved despite the large deformations obtained, since the plastic deformation of the steel section was very large (Figure 11B). The steel cross-section not only provided high ductility to the joints of reinforced concrete but also allowed the structure to have a plastic adaptation capacity. 


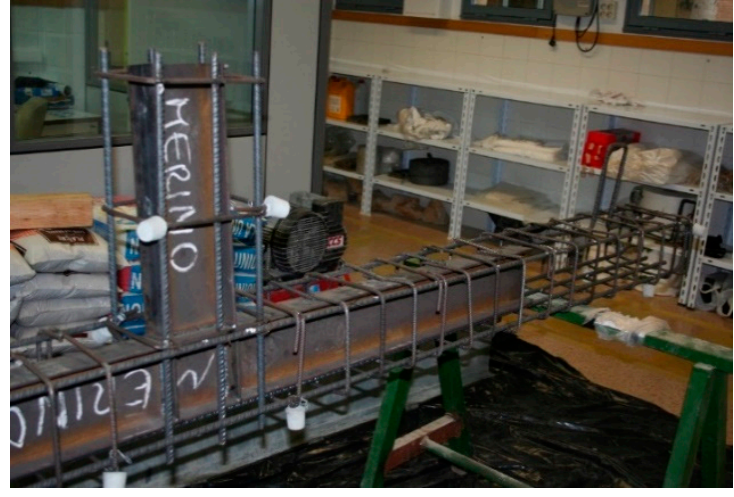

(A)

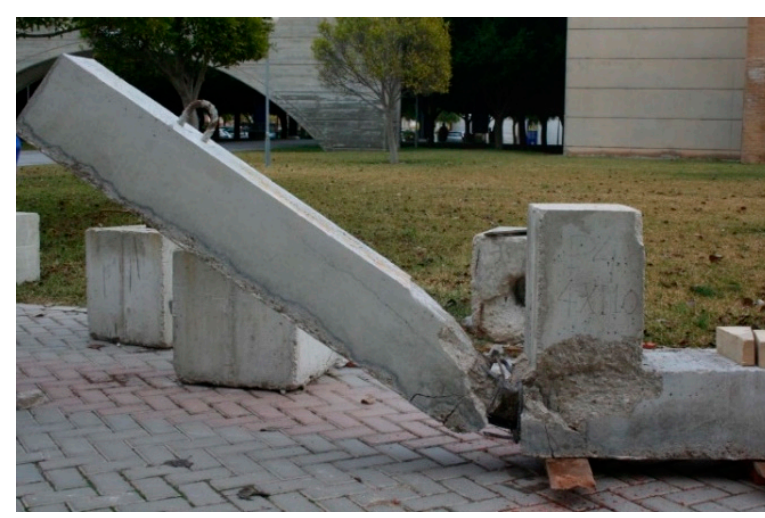

(B)

Figure 11. Specimen P04 in its execution phase (A) and image of the tested specimen P04 (B).

In the pre-break phase the entire section was plasticized. The concrete lost its tensile and compression resistant capacity, and detached from the section. The reinforcements were plasticized and were sectioned and no longer had resistant capacity. The metal profile continued to maintain a certain strength capacity with large deformations due to its high ductility. The neutral axis continued to rise, especially if the reinforcement was plasticized, since to balance any increase in momentum it is necessary to increase the mechanical arm of the internal forces, because these cannot vary. Figures 12 and 13 show the force-displacement results of the tested specimens.

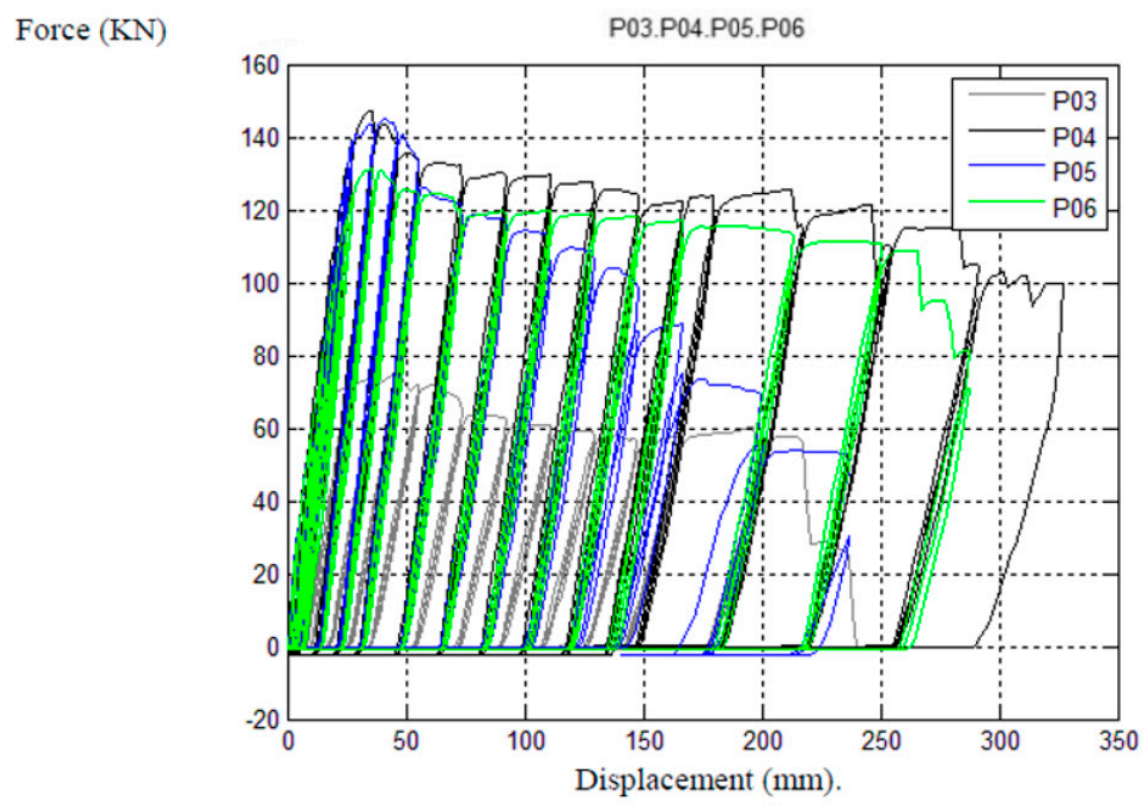

Figure 12. Comparative graph of the behavior of specimens P03, P04, P05 and P06. 


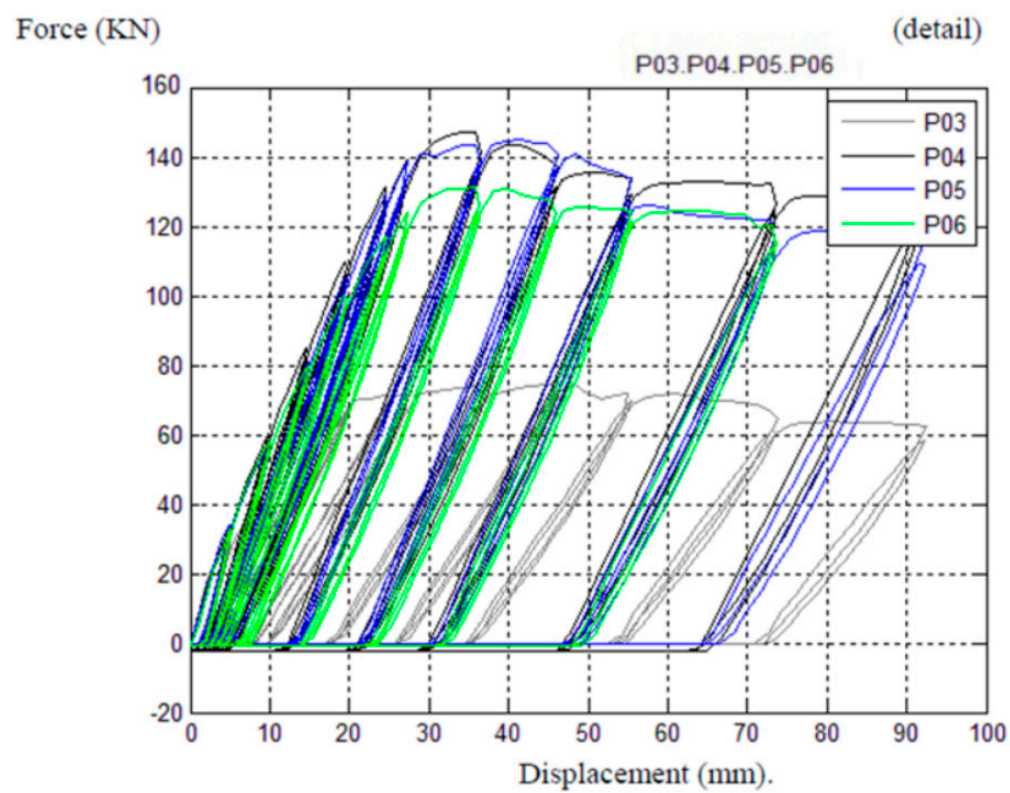

Figure 13. Comparative graph of the behavior of the specimens P03, P04, P05 and P06 (in detail).

In the initial loading and unloading cycles (shown in detail in Figure 12), the first load was elastic and the second unload was strikingly similar to the first one as no plastic deformation took place.

There was plastic deformation of the material and a reduction in the section resistance in the last cycles due to the elastic branch and another almost horizontal plastic area where the deformation grew without the load increasing.

Figure 14A,B illustrates how the concrete in the upper part of the critical section was dislodged by the buckling reinforcements.

The bars were compressed, the upper steel cross-section flange buckled and even the first broken stirrup confined the compressed concrete. The concrete confined between the core of the web and the flanges did not come loose, which ensured the friction bond between the two materials without having to design connectors as in other types of mixed structures.

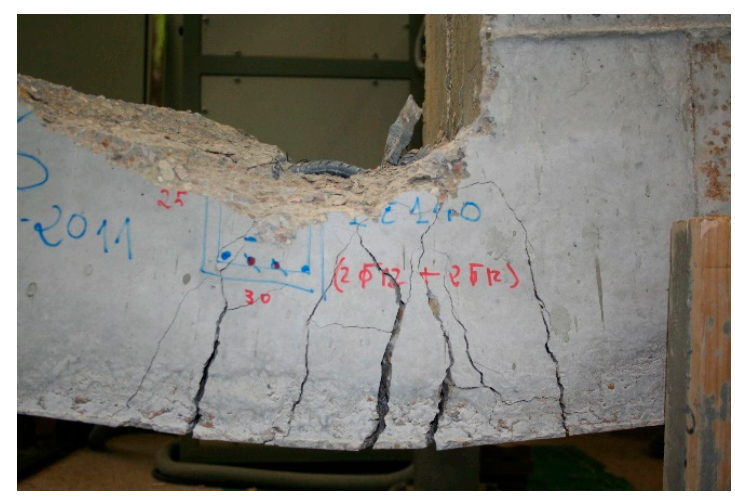

(A)

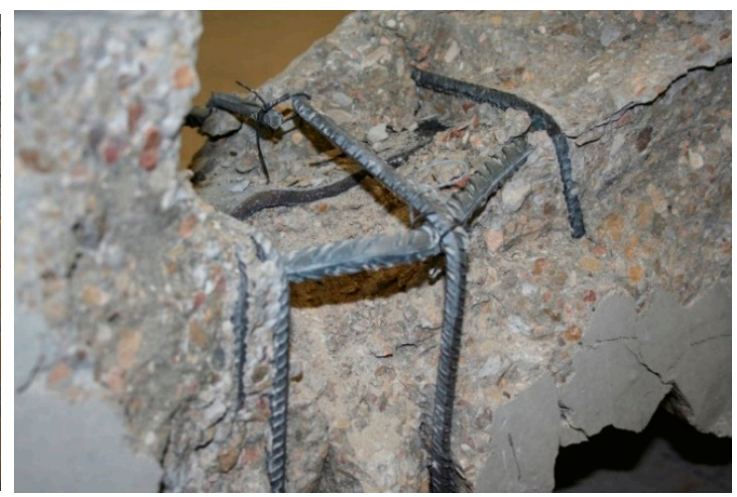

(B)

Figure 14. The specimen $\mathrm{P} 06$ at the end of the test (A) and a detail (B).

The reinforcement bars of specimen P07b were the same as those of specimen P07a. Specimen $\mathrm{P} 07 \mathrm{~b}$ was created after realizing that the plastic hinge appeared prematurely in the transition between the hollow cross-section and the reinforced concrete section while testing specimen P07a.

It was verified that the transition had to be carried out properly for the hinge to appear in the joint as opposed to the previous test, in which this transition appeared at the point where the embedded cross-section ended. 
The transition at the edge of the tubular cross-section and the breakage of the specimen in the section close to the joint was shown to be exactly the same as the previous specimens, except for specimen P07a. The concrete in the section near the joint was broken off, with almost the whole outer part having broken off in the most damaged zone (Figure 15).

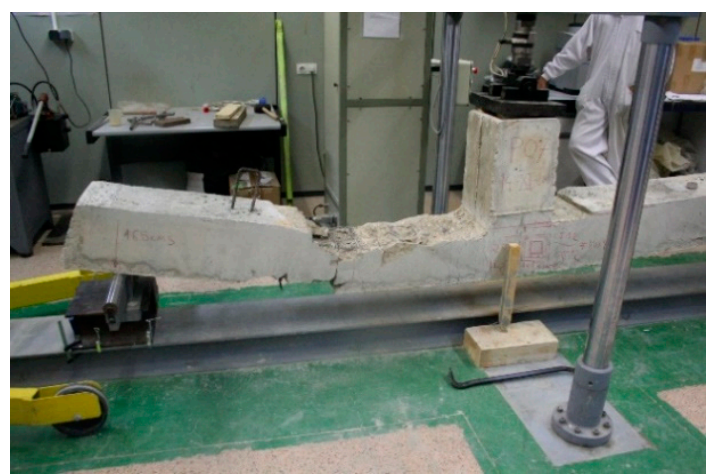

(A)

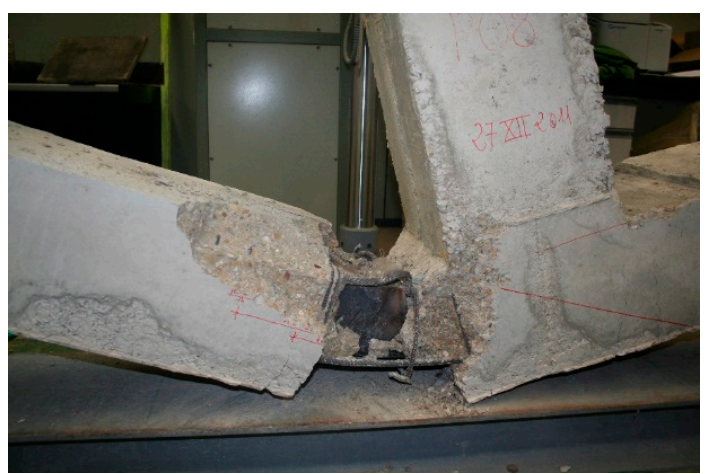

(B)

Figure 15. Detail of specimen P07a, (A), and P07b, (B).

The reinforced bars broke while the stirrup opening and the top of the tubular cross-section buckled although the concrete confined inside maintained a good appearance. The results can be seen in Figure 16.

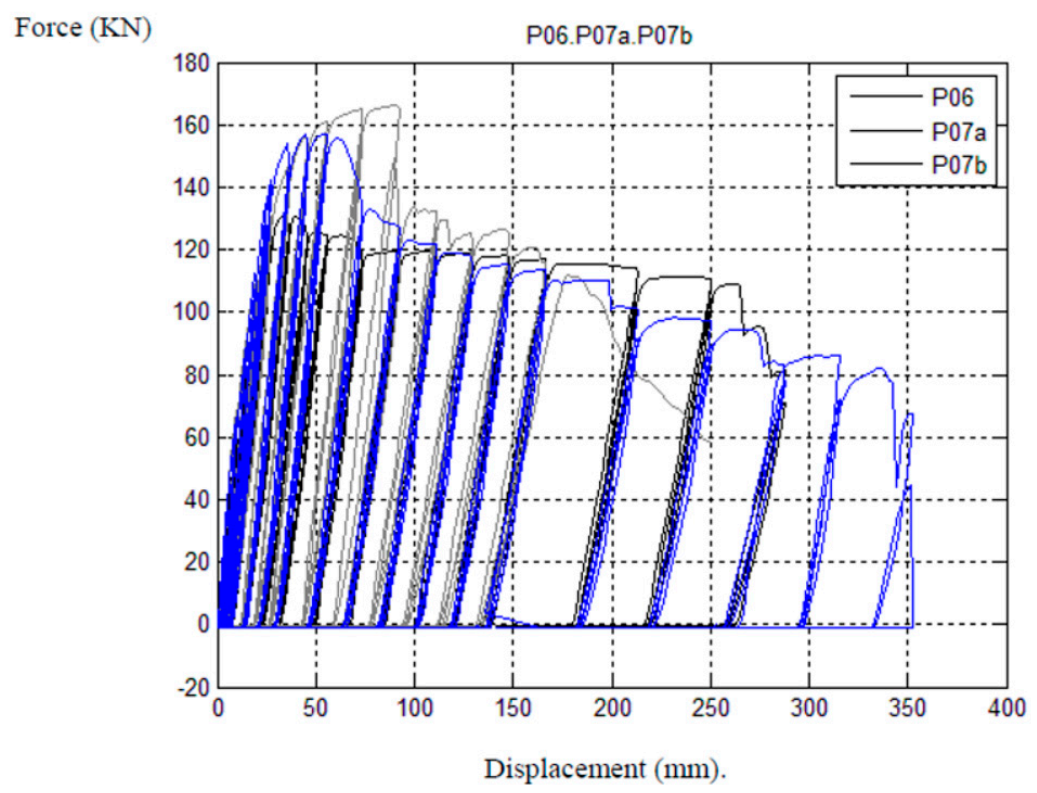

Figure 16. Comparative graph of the behavior of specimens P06, P07a and P07b.

The thickness of $5 \mathrm{~mm}$ for the tubular cross-section was insufficient and a thicker tubular cross-section that increases the joint's ductility must be designed in future tests.

Figure 17 is a summary of the force-displacement envelope curves of the tested specimens P03, P04, P05, P06 and P7b, which were realized to compare the results. Figures 12 and 16 show the real detailed data of the tests with loads and unloads. 


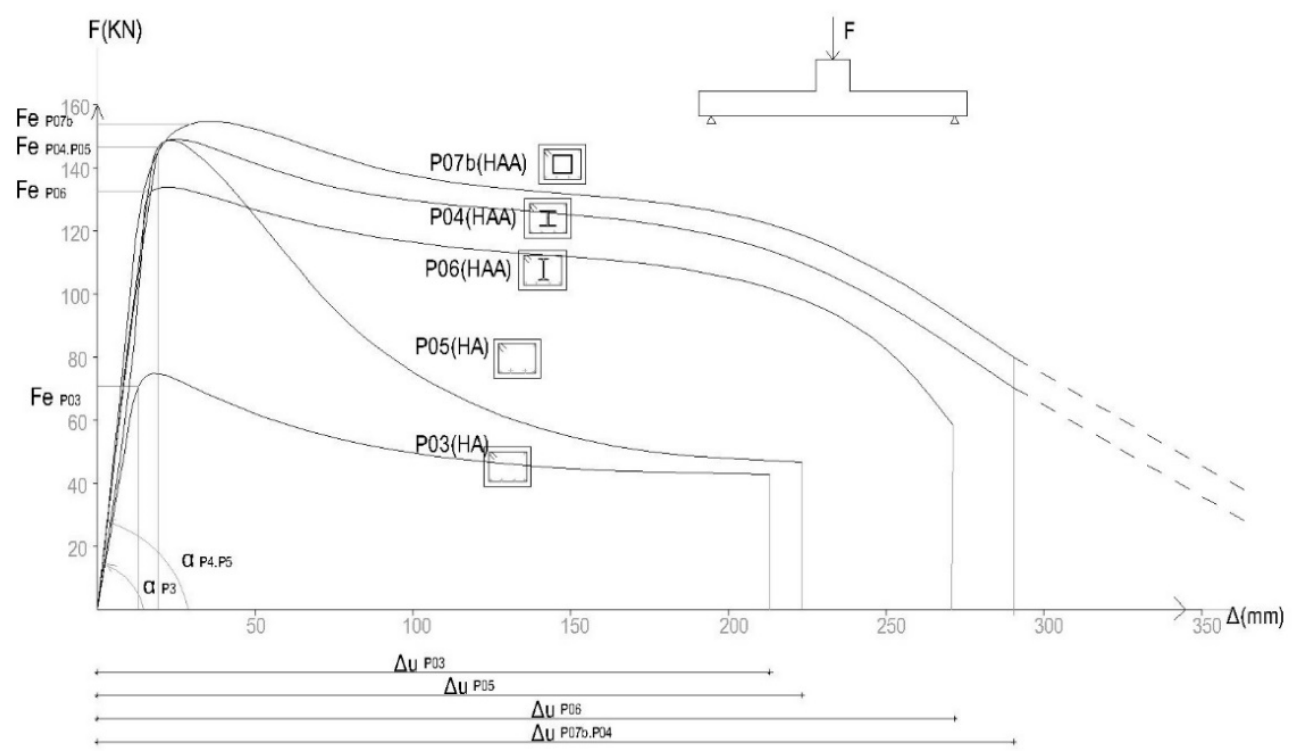

Figure 17. Summary of the experimental results obtained in specimens P03, P04, P05, P06 and P07b (Fe = Maximum Experimental Force).

The slope of the graph depends on the modulus of elasticity and this showed a clear increase in the stiffness of the specimen P04 steel reinforced concrete compared to the specimen P03 reinforced concrete. It can be observed that the stiffness is greater in the SRC joints than in the RC ones, depending on the cross-sectional area and the reinforced bars.

The energy absorbed by the structure is the area enclosed by the abscissa and the curves of the graph. The energy absorbed by the structure in specimen P04 is $21.77 \mathrm{kN} \cdot \mathrm{m}$ higher than that absorbed by specimen P05 but with equal maximum resistance, which was $30.23 \mathrm{kN} \cdot \mathrm{m}$ greater than specimen P03.

Specimen P04 absorbed three times more energy than specimen P03 (with no embedded cross-section). The ultimate deformation was appreciably greater in the SRC structures, which acted as steel structures in the deformations that came close to the break compared to the SR structures, whose ultimate break was fragile.

\section{Conclusions}

Based on the results obtained in the present article, the following conclusions are drawn:

- The results of using the conventional test frame with a loading-unloading cycle are comparable to those conducted with more complex frames in which loads have been applied with the opposite direction.

- The specimens of SRC showed improved resistance and ductility compared to specimens of reinforced concrete. The specimens of steel reinforced concrete can reach very high deflections before their collapse.

- For high deformations, a specimen with a square tube cross-section has considerably less resistance compared to the HEB cross-section due to the greater flexural efficiency of the steel cross-section. The specimen of steel reinforced concrete with a tubular cross-section with greater thicknesses achieved the most efficient ratio. This would allow better appreciation of the advantage of confined concrete.

- The studied typology with only partial steel cross-section reinforcement is a very interesting solution that can be incorporated to improve reinforced concrete structures' mechanical behavior.

- The energy absorbed by the structure in the specimen with steel reinforced concrete is higher than that absorbed by the specimen with reinforced concrete. 
- The crack pattern of all the specimens of steel reinforced concrete joints is quite similar to that of reinforced concrete joints.

- The tubular cross-section with the concrete inside used to create the steel reinforced concrete has better behavior in terms of bending strength. This is the normal situation against a seismic action.

Author Contributions: I.M. and R.I.; methodology, investigation, writing original and review, supervision; J.C.P. and A.G.; investigation and writing review.

Funding: This research received no external funding.

Conflicts of Interest: The authors declare no conflict of interest.

\section{References}

1. Architectural Institute of Japan (AIJ). AIJ Standards for Structural Calculation of Steel Reinforced Concrete Structures; Architectural Institute of Japan (AIJ): Tokyo, Japan, 2001.

2. Furlong, R.W. Strength of Steel-Encased Concrete Beam Columns. J. Struct. Div. 1967, 93, 113-124.

3. Wakabayashi, M. Design of Earthquake-Resistant Buildings; CRC Press: Boca Raton, FL, USA, 1986.

4. Mirmiran, A.; Shahawy, M. Behavior of concrete columns confined by fiber composites. J. Struct. Eng. 1997, 123, 583-590. [CrossRef]

5. Gioncu, V.; Petcu, D. Available rotation capacity of wide-flange beams and beam-columns Part 1. Theoretical approaches. J. Constr. Steel Res. 1997, 43, 161-217. [CrossRef]

6. Gioncu, V.; Petcu, D. Available rotation capacity of wide-flange beams and beam-columns Part 2. Experimental and numerical tests. J. Constr. Steel Res. 1997, 43, 219-244. [CrossRef]

7. Chen, C.C.; Lin, K.T. Behavior and strength of steel reinforced concrete beam-column joints with two-side force inputs. J. Constr. Steel Res. 2009, 65, 641-649. [CrossRef]

8. Tong, L.; Liu, B.; Xian, Q.; Zhao, X.-L. Experimental study on fatigue behavior of Steel reinforced concrete beams. Eng. Struct. 2016, 123, 247-262. [CrossRef]

9. Giménez Carbó, E. Estudio experimental y numérico de soportes de hormigón armado reforzados con perfiles metálicos sometidos a esfuerzos de compresión simple. Ph.D. Thesis, Universidad Politécnica de Valencia, València, Spain, 26 June 2007. (In Spanish).

10. Figueirido, D.H. Estudio experimental del pandeo de perfiles tubulares rectangulares de acero, rellenos de hormigón de alta resistencia, bajo carga axial y diagrama de momentos variables. Ph.D. Thesis, Universidad Politécnica de Valencia, València, Spain, 10 February 2012. (In Spanish).

11. Chen, Z.; Xu, J.; Xue, J. Hysteretic behavior of special shaped columns composed of steel and reinforced concrete (SRC). Earthq. Eng. Eng. Vibr. 2015, 14, 329-345. [CrossRef]

12. Yan, C.; Yang, D.; Ma, Z.J.; Jia, J. Hysteretic model of SRUHSC column and SRC beam joints considering damage effects. Earthq. Eng. Eng. Vibr. 2017, 50. [CrossRef]

13. Chen, C.-C.; Suswanto, B.; Lin, Y.-J. Behavior and strength of steel reinforced concrete beam-column joints with single-side force inputs. J. Constr. Steel Res. 2009, 65, 1569-1581. [CrossRef]

14. Chen, S.; Wu, P. Analytical model for predicting axial compressive behavior of steel reinforced concrete column. J. Constr. Steel Res. 2017, 128, 649-660. [CrossRef]

15. Bossio, A.; Fabbrocino, F.; Lignola, G.P.; Prota, A.; Manfredi, G. Design Oriented Model for the Assessment of T-Shaped Beam-Column Joints in Reinforced Concrete Frames. Buildings 2017, 7, 118. [CrossRef]

16. Santarsiero, G. FE Modelling of the Seismic Behavior of Wide Beam-Column Joints Strengthened with CFRP Systems. Buildings 2018, 8, 31. [CrossRef]

17. Kabir, M.R.; Alam, M.S.; Said, A.M.; Ayad, A. Performance of Hybrid Reinforced Concrete Beam Column Joint: A Critical Review. Fibers 2016, 4, 13. [CrossRef]

18. Gribniak, V.; Tamulenas, V.; Ng, P.-L.; Arnautov, A.K.; Gudonis, E.; Misiunaite, I. Mechanical Behavior of Steel Fiber-Reinforced Concrete Beams Bonded with External Carbon Fiber Sheets. Materials 2017, 10, 666. [CrossRef] [PubMed]

19. Iqbal, S.; Ali, A.; Holschemacher, K.; Bier, T.A. Mechanical properties of steel fiber reinforced high strength lightweight self-compacting concrete (SHLSCC). Constr. Build. Mater. 2015, 98, 325-333. [CrossRef] 
20. Tran, M.-T.; Bui, Q.-B.; Sentosa, B.; Nguyen, N.-T.; Duong, T.-H.; Plé, O. Sustainable RC Beam-Column Connections with Headed Bars: A Formula for Shear Strength Evaluation. Sustainability 2018, 10, 401. [CrossRef]

21. ACI Committee 318. Building Code Requirements for Structural Concrete (ACI318-05) and Commentary (ACI 318R-05); American Concrete Institute: Farmington Hills, MI, USA, 2005.

22. EN 1994-1-1: Eurocode 4: Design of Composite Steel and Concrete Structures; The European Union: Brussels, Belgium, 2004.

(c)

(C) 2019 by the authors. Licensee MDPI, Basel, Switzerland. This article is an open access article distributed under the terms and conditions of the Creative Commons Attribution (CC BY) license (http://creativecommons.org/licenses/by/4.0/). 